\title{
Narrative review of palliative hypofractionated radiotherapy for high grade glioma
}

\author{
Hina Saeed ${ }^{1}$, Yolanda D. Tseng ${ }^{2}$, Simon S. Lo $^{2}$ \\ ${ }^{1}$ Department of Radiation Oncology, Medical College of Wisconsin, Milwaukee, WI, USA; ${ }^{2}$ Department of Radiation Oncology, University of \\ Washington School of Medicine, Seattle, WA, USA \\ Contributions: (I) Conception and design: All authors; (II) Administrative support: All authors; (III) Provision of study materials or patients: All \\ authors; (IV) Collection and assembly of data: All authors; (V) Data analysis and interpretation: All authors; (VI) Manuscript writing: All authors; (VII) \\ Final approval of manuscript: All authors. \\ Correspondence to: Hina Saeed, MD. 9200 W Wisconsin Av, Brookfield, WI 53226, USA. Email: hisaeed@mcw.edu.
}

\begin{abstract}
High grade gliomas (HGG) include World Health Organization (WHO) grade III anaplastic astrocytoma (AA) and WHO grade IV glioblastoma (GBM). As genomic alterations are prognostic, even WHO grade II, IDH-wildtype gliomas may be considered as HGG. Current management of HGG include best supportive care (BSC), surgery, radiation therapy (RT), chemotherapy, and a combination. Elderly patients (defined here as age $\geq 65$ ) with GBM have significantly worse survival compared to younger patients. Similarly, patients with poor performance status [defined as Karnofsky performance status (KPS) $<60$ or ECOG performance status (PS) >2], regardless of age have worse outcomes. The standard of care for treatment of HGG involves surgery and chemoradiation. However, the optimal treatment in terms of efficacy, safety and maintaining quality of life (QoL), remains a matter of debate in the elderly and/or poor performing patients due to their worse prognosis. Less aggressive interventions are usually reserved for these patients despite surgery providing a survival and neurologic benefit. Improved survival has been noted in elderly patients treated with RT in comparison with those receiving best supportive care (BSC) alone, with similar survival for patients undergoing standard RT (60 Gy/30 fractions) and hypofractionated RT (25-40 Gy in 5-15 daily fractions). An alkylating agent, temozolomide (TMZ), represents a safe and effective option in select patients with promoter methylation of O6-methylguanine-DNA-methyltransferase (MGMT) gene. A recent phase III randomized trial for GBM patients (age $\geq 65$ years, ECOG PS 0-2) demonstrated a significant improvement in progression-free survival (PFS) and overall survival (OS) with hypofractionated RT (40 Gy/15 fractions) with concurrent and adjuvant TMZ vs. RT alone, without adversely impacting either QoL or functional status. Despite chemoradiation becoming the recommended treatment in GBM patients who are elderly but fit, several questions remain unanswered. This includes the survival impact of chemoradiation in patients with severe comorbidities or with ECOG PS $>2$ or a combination of poor prognostic features such as male gender, poor neurocognition, biopsy only and lack of MGMT methylation. Personalized management of patients with HGG is warranted in the modern era as we attempt to balance the benefit of efficacious treatment with potential toxicity while appreciating the many nuances associated with multiple prognostic factors on anticipated survival. Here, we aim to review the palliative management options available for HGG patients with an emphasis on the role of RT.
\end{abstract}

Keywords: Glioma; glioblastoma (GBM); palliation; radiotherapy; hypofractionation

Submitted Jun 10, 2020. Accepted for publication Sep 03, 2020.

doi: 10.21037/apm-20-1246

View this article at: http://dx.doi.org/10.21037/apm-20-1246 


\section{Introduction}

Gliomas constitute almost $80 \%$ of all primary malignant brain tumors with an incidence of 3.2/100,000 for glioblastoma $(\mathrm{GBM})$ in the United States $(1,2)$. Median age at diagnosis of GBM is 64 (3). The incidence and mortality rate of GBM increases with advanced age (4,5). Ladomersky reported a 3.4 times higher incidence of GBM and 7 times higher mortality rate among individuals age $\geq 65 \mathrm{vs}$. age $<65$ respectively (6). Furthermore, as the collective world population survives longer, the proportion of elderly GBM patients is predicted to increase as well. These observations highlight the current and future public health needs in managing elderly GBM patients (7).

Approximately, 54\% of gliomas are GBMs $(8,9)$ with IDH-mutant GBMs making up about $<10 \%$ of all GBMs $(2,10)$. IDH-mutant GBMs occur in younger adults (mean age 45 years) compared with IDH-wild type (wt) GBMs (mean age $>55$ years), and have a more favorable prognosis, with a median survival $\sim 2 \times$ longer than that of IDHwildtype tumors $(11,12)$. In a study that reclassified 1,210 gliomas samples according to updated 2016 WHO CNS diagnostic criteria, GBM with IDH-wt was associated with the highest median age at diagnosis (median age 50) (13). Similarly, $65 \%$ of AA are IDH-mutant and occur more often in younger patients ages $30-50(14,15)$.

The classification of gliomas is an actively evolving field with much of the historical outcome data based on conventional histopathological features. However, recent developments of molecular and genetic factors have allowed us to create subsets that show more accurate and meaningful correlation between their perceived and actual outcomes. Table 1 depicts the range of gliomas categorized as HGG.

The median survival for GBM is 15 months (16) and for AA is 36 months (17). Age and performance status (PS) as measured by WHO PS or Karnofsky performance status (KPS) can significantly impact survival and are illustrative of the two most important prognostic factors in GBM (18-21). This has been shown by large retrospective studies reporting a median survival of 6 months for GBM patients (age >65) versus 14.6 months for patients in the randomized controlled trial by Stupp (median age 56 years old) (22-26). A multivariate analysis of three randomized Radiation Therapy Oncology group (RTOG) protocols using standard radiation therapy (RT) and chemotherapy for GBM showed reported a median survival of 24 weeks for patients greater than 60 years of age (27). Other factors associated with poor prognosis include differences in the GBM biology such as higher incidence of IDH-wt $(11,28,29)$, agerelated variations in the central nervous system (CNS) that augment gliomagenesis and proliferation (30), male gender, lack of MGMT methylation, biopsy only and poor neurocognition (31).

While the current standard of care for younger, good performing patients includes surgical resection, concurrent chemoradiation with temozolomide (TMZ) and adjuvant TMZ for GBMs or the recently suggested regimen of adjuvant TMZ/lomustine for methylated GBMs (26,32,33), the maximally-effective treatment of geriatric or poor PS GBM patients had not been clearly defined. This lack of data is a direct of consequence of traditional exclusion of patients over the age of 70 years from clinical trials, due to their presumed decreased prospect of a sustained treatment response and/or a good outcome. Additionally, all the patients enrolled in the Stupp and Herrlinger trials had a PS $\leq 2$ (corresponding to KPS $\geq 60$ ) and KPS $\geq 70$ respectively. Of note, among patients treated in the Stupp trial, older patients (65-70 years) appeared to derive less benefit with chemoradiation compared to younger patients $(\mathrm{HR}=0.78$; $\mathrm{P}=0.29$ ) (34).

Complicating this aforementioned lack of data are factors such as higher frequency of age-related-polypharmacy, medical co-morbidities and an increased likelihood of treatment-related toxicity, that results in controversy regarding optimal treatment paradigm for elderly and/or poor PS GBM patients $(26,35,36)$. These patients are less likely to receive aggressive surgery, radiation, chemotherapy, or combined modality treatment. A probable increased risk of perioperative complications, radiation induced fatigue and cognitive decline and chemotherapy induced hematologic effects can culminate in hesitation to employ those modalities. The social situation of these patients must also be considered. Usually, caregivers of elderly patients who embrace the physical, financial, temporal, emotional and social expenses associated with scheduling, billing, transporting and assisting a loved one are often elderly themselves $(37,38)$. This can potentially exacerbate any medical, economic, and psychosocial risks for both the patient and the caregiver, and underscores need for constant communication and support between medical providers and the patients during the entire treatment journey. This necessitates subsequent thoughtful use of treatment options to improve survival without adding excessive toxicities or adversely impacting QoL.

Herein, we aim to review the evolution and use of upfront hypofractionated radiation for patients with poor prognosis 
Table 1 Entities included in HGG (Louis 2016, Brat 2018, Bale 2019)

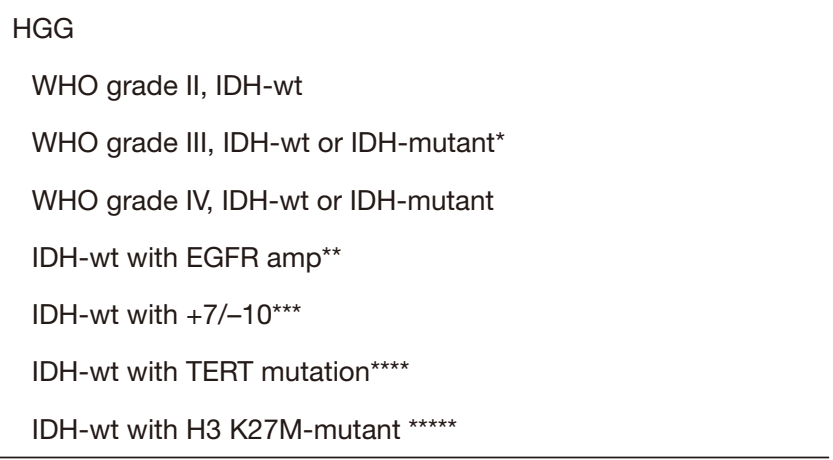

HGG, high grade gliomas. *Prognosis better for IDH-mutant compared with IDH-wt, ${ }^{* *}$ epidermal growth factor receptor (EGFR) amplification, ${ }^{* \star *}$ chromosome 7 gain/chromosome 10 loss, ${ }^{* \star *}$ telomerase reverse transcriptase (TERT) promotor mutation, ${ }^{\star \star \star \star \star}$ diffuse midline glioma.

(Table 2) that were historically managed with BSC. One can argue that any conventional treatment for GBM is palliative. However, for simplicity, we are defining "palliative" as any regimen which is more contracted than the conventional standard radiation regimen. Detailed role of surgical treatments, systemic options and tumor treating fields are out of the scope of this review but will be briefly described to cover the available treatment options for patients with poor prognosis. The last two decades has been marked with accelerated development in surgery and radiation techniques as well as radiation fractionation schedules and chemotherapy with enhanced toxicity profile, convenient scheduling and straightforward administration such as TMZ, making these more appropriate for delivery in the palliative setting for GBM patients. Since there have been no trials specifically looking at HGGs other than GBMs, we will be looking at the available data for palliative treatment of GBM and use it to extrapolate to other non-GBM HGGs. We present the following article in accordance with the NARRATIVE REVIEW reporting checklist (available at http://dx.doi.org/10.21037/apm-20-1246).

\section{Methods}

MEDLINE and EMBASE were searched using the terms "glioblastoma" or "gbm" or "high grade glioma" and "palliative" or "hypofractionation" or "hypofractionated radiotherapy" from 1975 through June 2020. The references of retrieved articles were searched. Relevant book chapters
Table 2 Factors associated with poor prognosis in HGG patients

Poor prognostic signs for HGG patients
Increasing age (defined here as $\geq 65$ )
Poor performance status (KPS $<60$, ECOG PS $>2$ )
Biopsy only
Male gender
Absence of MGMT methylation
IDH-wt
Poor neurocognition
Lack of radiation and/or chemotherapy
Recurrent high grade glioma

HGG, high grade gliomas. KPS, Karnofsky performance status; PS, performance status; MGMT, O6-methylguanine-DNAmethyltransferase.

were reviewed. Websites of various oncologic societies were hand-searched for guidelines. Any papers including only pediatric gliomas or low-grade gliomas were excluded.

\section{Discussion}

\section{Role of surgery}

The role of surgery in the case of palliative treatment of HGG remains controversial. Ethical concerns have precluded any prospective studies evaluating the consequences of aggressive versus limited resection. In a Surveillance, Epidemiology, and End Results (SEER) database study of 20,705 GBM patients, the frequency of gross total resection (GTR) decreased as function of age [36\% (18-44 years) vs. $24 \%$ ( $>75$ years), $\mathrm{P}<0.001]$. Nevertheless, a 2-3-fold increase in overall survival (OS) was associated with GTR (39). Similarly, an Austrian study found a significantly improved OS associated with subtotal resection (STR) or GTR (median 11.0 and 15.0 months respectively) compared with partial resection or biopsy (median 4.0 months each) (40).

A large meta-analysis of 34 studies involving 12,607 older patients showed significant improvement in progression free survival (PFS) and OS associated with either STR or GTR versus a biopsy only approach. GTR was significantly superior to STR in terms of OS, PFS, improvement in KPS and no changes in mortality or morbidity (41). However, this improvement may demonstrate the heterogeneity of the elderly population and can be driven by other 
factors such as higher pre-operative PS and receipt of adjuvant therapy (42). Vuorinen et al. reported on a small randomized prospective study of 30 patients, three-fourths of which had malignant glioma. They reported significantly longer survival for patients undergoing surgery compared with a biopsy (171 vs. 85 days; $\mathrm{P}=0.03$ ) with no significant differences in neurologic decline (43). D'Amico et al. showed an overall rate of complications of $22 \%$, with a rate of neurological complications of $8 \%$ after surgical resection in $274 \mathrm{GBM}$ patients ( $>65$ years). He reported decreased risk of complications in younger and better functional status patients (44).

Despite evidence favoring aggressive surgical resection in carefully selected elderly GBM population, increasing age is associated with a decreased probability of undergoing surgery $(25,41,43,45-47)$. The results of a French phase III trial assessing the significance of surgery on the treatment of patients (age $\geq 70$ ) with supratentorial malignant gliomas are eagerly awaited (NCT02892708).

\section{$R T$ with standard fractionation (SRT)}

The median survival benefit of postoperative RT for GBM compared with BSC alone (37.5 vs. 17 weeks) was first proven by the Brain Tumor Study Group randomized trial (48) with $60 \mathrm{~Gy} / 30$ fractions established as the best treatment regimen $(49,50)$. The EORTC trial established postoperative concurrent chemoradiation followed by adjuvant TMZ as the standard of care with statistically significant survival benefit (26).

However, the management of patients who are elderly ( $>70$ years) and/or poor PS remains a gray zone are as they were typically deemed not eligible for clinical trials (3). The traditionally used recursive partitioning analysis (RPA) to categorize HGG into different prognostic groups excluded patients age 70 or older (25). Furthermore, retrospective series has shown the overall relative risk of death in GBM patients to be 1.70 and 2.65 for patients in the $70-79$ and 80 or older age groups compared with patients in the 60-69 age groups (51). In the absence of high mortality and lack of data, the value of radiotherapy was questioned for patients with poor prognosis.

A shift in paradigm occurred with the French Phase III trial of 81 GBM patients (age $\geq 70$ years; KPS $\geq 70$ ) showing statistically significant improvement in median survival with postoperative SRT (50.4 Gy/28 fractions, 29.1 weeks) versus BSC alone (16.9 weeks) without any severe adverse events or differences in QoL and neurocognition (52).
Despite there being level 1 evidence demonstrating the superiority of radiotherapy (RT) over BSC (an absolute gain of 12.2 weeks but without extending acceptable lifeyears), it is vital to consider the significant time spent in the radiation oncology clinic for treatment. This can have an adverse effect on patients' and their caregiver's QoL, socioeconomic aspects and is perhaps not the best use of limited resources (53). From a logical standpoint, this resulted in efforts to reduce the intensity and duration of the treatment of patients with poor prognosis in order to optimize survival and minimize inconvenience due to treatment, socioeconomic and financial logistics.

\section{Retrospective studies evaluating bypofractionated radiotherapy (HRT) alone}

With the acknowledgment of the benefit of RT compared with BSC, there was a heightened awareness for evaluating contracted regimens to optimize the QoL of patients with poor prognosis and minimize treatment time. Several retrospective studies have been performed to evaluate the efficacy and toxicity outcomes associated with HRT for GBM or HGG (Table 3). A few are described below and laid the groundwork for prospective trials. Overall, these studies suggested a benefit from radiotherapy in the poor prognosis group without significant detriment in quality of life (QoL). Furthermore, the hypofractionated regimens seemed to be non-inferior to the conventional regimens (54-58).

\section{Prospective studies evaluating HRT or systemic therapy alone}

Based on promising retrospective data, a number of shorter-course radiation schedules for poor prognosis patients were prospectively evaluated, with the intent to further confirm the previous findings (Table 4). The results of these prospective trials reinforced the outcomes seen in retrospective studies. Overall, the hypofractionated regimens were well-tolerated and retained efficacy similar to conventional regimens. Median survival ranged from 4 to 7.6 months (59-63). Hypofractionated intensity-modulated radiotherapy (IMRT) alone was attempted but failed to improve the OS compared with historical control using standard fractionation $(64,65)$. However, the decreased treatment duration from 6 to 2 weeks, using the accelerated schedule, may offer convenient palliation for a select group of patients.

The suggestion of encouraging outcomes by single arm 
Table 3 Selected series of retrospective hypofractionated radiotherapy

\begin{tabular}{|c|c|c|c|c|c|}
\hline Study & Type & Patient selection & No. of patients & Fractionation & Median survival (months)/toxicities \\
\hline Kleinberg (55) & Retrospective & All patients & 219 & 3 Gy ×17 & $\begin{array}{l}\text { RPA class-IV: } 13, \mathrm{~V}: 8 \text {, VI: } 5 \text {. Radiation necrosis } \\
\text { in } 1 \text { patient }\end{array}$ \\
\hline McAleese (57) & $\begin{array}{l}\text { Prospective/ } \\
\text { retrospective }\end{array}$ & $\begin{array}{l}\text { Age } \geq 50 \mathrm{yr} \text { and } \mathrm{KPS} \\
\leq 90\end{array}$ & 92 & 5 Gy ×6 & $\begin{array}{l}\text { 5. RT related toxicities not specifically reported, } \\
\text { Neurologic deterioration in } 3 \% \text { of patients }\end{array}$ \\
\hline Lutterbach (58) & Retrospective & Age $\geq 60 \mathrm{yr}$ & 50 & 3.5 Gy ×12 & 7.3. No grade $\geq 3$ toxicities \\
\hline
\end{tabular}

KPS, Karnofsky performance status; RPA, recursive partitioning analysis; RT, radiotherapy.

Table 4 Selected series of prospective shorter-course radiotherapy regimens

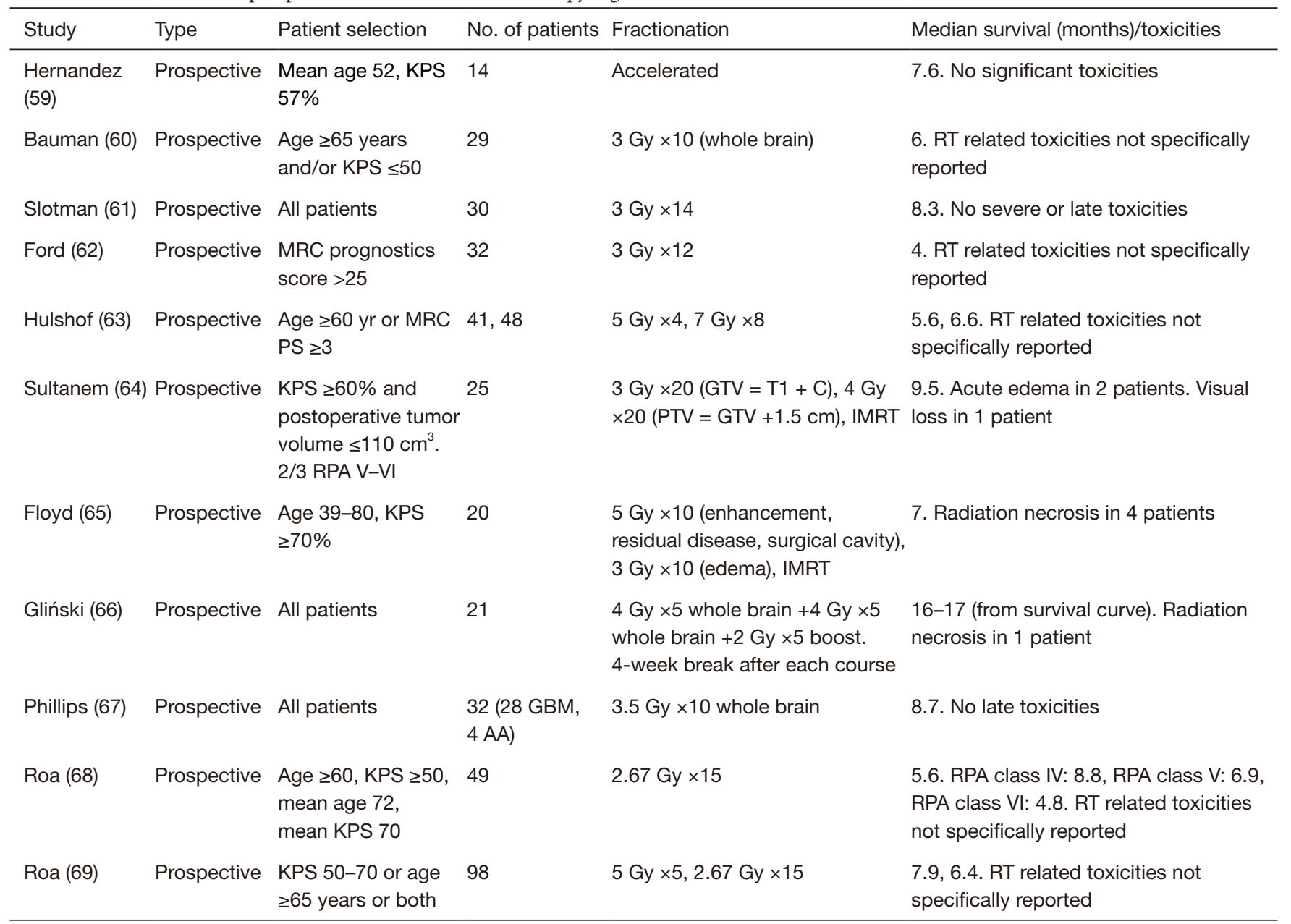

IMRT, intensity modulated radiation therapy; KPS, Karnofsky performance status; RPA, recursive partitioning analysis; GBM, glioblastoma;

IMRT, intensity-modulated radiotherapy; RT, radiotherapy; PTV, planning target volume. 
Table 5 Selected series of hypofractionated radiation (HRT) with adjuvant chemotherapy

\begin{tabular}{llllll}
\hline Study & Type & Patient selection & $\begin{array}{l}\text { No. of } \\
\text { patients }\end{array}$ & Treatment & Median survival (months)/toxicities \\
\hline Minniti (73) & $\begin{array}{l}\text { Prospective, phase II } \\
\text { Age } \geq 70 \text { years and } \\
\text { KPS } \geq 60\end{array}$ & 43 & $\begin{array}{l}5 \text { Gy } \times 6 \text { (2 weeks) + } \\
\text { adjuvant TMZ (12 cycles) }\end{array}$ & $\begin{array}{l}\text { OS 9.3, PFS 6.3. Grade 3-4 hematologic } \\
\text { toxicity in 28\% with TMZ }\end{array}$ \\
Muni (74) & $\begin{array}{l}\text { Prospective, } \\
\text { randomized phase II }\end{array}$ & $\begin{array}{l}\text { Age }>70 \text { yrs or age } \\
\leq 70 \text { yrs with KPS }<70\end{array}$ & $\begin{array}{l}5 \text { Gy } \times 6 \text { vs. } 5 \text { Gy } \times 6+ \\
\text { adjuvant TMZ }\end{array}$ & $\begin{array}{l}\text { OS 7.3 vs. 9.4. Grade 3-4 hematologic } \\
\text { toxicity in } 30 \% \text { with TMZ }\end{array}$ \\
\hline
\end{tabular}

KPS, Karnofsky performance status; TMZ, temozolomide; OS, overall survival; PFS, progression-free survival.

prospective studies soon led to randomized trials comparing standard fractionation with hypofractionation for patients with HGG. Both the split course hypofractionated regimen and hypofractionated whole brain regimen groups were tolerated well and compared favorably in terms of survival with standard arm $(66,67)$.

The aforementioned results established the safety of hypofractionation, resulting in a need to test the feasibility of this approach in patients with poor prognosis. In a pivotal phase III Canadian study, 100 elderly GBM patients received either SRT (60 Gy/30 fractions) or HRT (40 Gy/15 fractions) to the partial brain. The results of the median survival demonstrated the non-inferiority of HRT (5.6 months) versus SRT (5.1 months) (68). A subsequent phase III trial randomized 98 patients to two different hypofractionated schedules, 25 Gy/5 fractions (1 week) or 40 Gy/15 fractions (3 weeks). Similar outcomes were noted for median survival, PFS or QoL at 4- and 8-weeks posttreatment (69). This trial notably included both elderly as well as poorly performing patients (KPS 50-70). However, it did not include the assessment of any benefit from TMZ chemotherapy.

A randomized phase III German NOA-08 trial looked at the question of TMZ and demonstrated its noninferiority with a 7-day-on/7-day-off schedule compared with SRT alone (60 Gy/30 fractions) for $412 \mathrm{GBM}$ or AA patients (KPS $\geq 60$, age $\geq 65$ years). The median OS was 9.6 months in the SRT arm compared with 8.6 months in the TMZ arm. Improved median OS was correlated with MGMT promoter methylation (11.9 months) compared with unmethylated tumors (8.2 months). Improved PFS for MGMT methylated tumors treated with TMZ and unmethylated tumors treated with SRT was observed. No differences in health related QOL was detected (70). The same year, a randomized phase III Swedish Nordic trial comparing SRT (60 Gy/30 fractions), HRT (34 Gy $/ 10$ fractions), and TMZ (up to 6 cycles) in 342 GBM patients (age $>60$ ) showed similar median OS for patients treated with TMZ or HRT (8.4 vs. 7.4 months; $\mathrm{P}=0.12$ ). Notably, TMZ or HRT resulted in significantly better survival compared with SRT for patients over 70 years. Improved OS with TMZ was again noted for patients with MGMT promoter methylation (9.7 vs. 6.8 months, $\mathrm{P}=0.02)(71)$.

With NOA-08 and Nordic trials only including patients with KPS $\geq 60$ and ECOG $0-2$ respectively, they evaluated treatments for elderly but fit GBM patients. Furthermore, the suggestion of survival benefit by TMZ was largely restricted to MGMT methylated tumors. MGMT promoter methylation is highly predictive for benefit from TMZ. This was in contrast to benefit by RT which was independent of MGMT promoter methylation.

\section{HRT administered with adjuvant chemotherapy}

After Hegi et al.'s seminal trial in 2005 and designation of MGMT promoter methylation as a predictor of benefit from TMZ treatment (72), GBM studies on HRT for poor prognosis patients started including TMZ (Table 5). Due to toxicity concerns with concurrent chemotherapy, initial hypofractionation studies were performed with adjuvant chemotherapy. Both trials reported an independent significant association of KPS with survival. Notably, no worsening of QoL was noted other than progressive exacerbation of fatigue $(73,74)$.

\section{HRT administered with concurrent chemotherapy}

The safety of HRT with adjuvant chemotherapy prompted studies with hypofractionation and concurrent chemotherapy. Lim et al. retrospectively reviewed 33 GBM patients (age $\geq 70$ years or risk factors including poor PS, rapidly progressive disease or biopsy only) who received HRT (median RT dose 45 Gy/15 fractions) with concurrent TMZ. With a median age of 66 and tolerable side-effects, the median OS was 10.6 months (75). 
Table 6 Selected series of hypofractionated radiation (HRT) with concurrent and adjuvant chemotherapy

\begin{tabular}{|c|c|c|c|c|c|}
\hline Study & Type & Patient selection & $\begin{array}{l}\text { No. of } \\
\text { patients }\end{array}$ & Arms & Median survival (months)/toxicity \\
\hline $\begin{array}{l}\text { Panet-Raymond } \\
\text { (76) }\end{array}$ & Retrospective & $\begin{array}{l}\text { All patients. Median } \\
\text { age } 63.75 \% \text { RPA } \\
\text { V/VI }\end{array}$ & 35 & $\begin{array}{l}3 \text { Gy } \times 20 \text { to GTV and } 2 \text { Gy } \times 20 \text { to } \\
\text { PTV with concurrent and adjuvant } \\
\text { temozolomide ( } 6 \text { cycles) }\end{array}$ & $\begin{array}{l}\text { 14.4. Grade } 3-4 \text { nausea/vomiting in } 1 \\
\text { patient }\end{array}$ \\
\hline Terasaki (77) & Prospective & $\begin{array}{l}\text { All patients, KPS } \\
\geq 50 \text {. Median age } 61 \text {, } \\
\text { median KPS } 60\end{array}$ & 26 & $\begin{array}{l}3 \text { Gy } \times 15 \text { with concurrent and } \\
\text { adjuvant temozolomide ( } 12 \text { cycles) }\end{array}$ & $\begin{array}{l}\text { 15.6. Grade } 4 \text { neutropenia: } 3 \text { patients, } \\
\text { grade } 4 \text { thrombocytopenia: } 1 \text { patient }\end{array}$ \\
\hline Minniti (78) & $\begin{array}{l}\text { Prospective, } \\
\text { phase II }\end{array}$ & $\begin{array}{l}\text { Age } \geq 70 \text { years, KPS } \\
\geq 60\end{array}$ & 71 & $\begin{array}{l}2.67 \text { Gy } \times 15 \text { with concurrent and } \\
\text { adjuvant temozolomide ( } 12 \text { cycles) }\end{array}$ & $\begin{array}{l}\text { 12.4. Grade } 3-4 \text { hematologic toxicity } \\
\text { in } 10 \text { patients, grade } 3 \text { fatigue in } 4 \\
\text { patients, grade } 3 \text { cognitive disability } \\
\text { in1 patient }\end{array}$ \\
\hline Ohno (79) & Retrospective & $\begin{array}{l}\text { Age } \geq 75, \mathrm{KPS} \geq 50, \\
\text { median age } 80,37 \% \\
\text { KPS } 50-60\end{array}$ & 30 & $\begin{array}{l}3 \text { Gy } \times 15 \text { and concurrent } \\
\text { temozolomide and adjuvant } \\
\text { temozolomide ( } 12-24 \text { cycles) or } \\
3 \text { Gy } \times 15 \text { and adjuvant } \\
\text { temozolomide/bevacizumab }\end{array}$ & $\begin{array}{l}\text { 12.9. Grade } 3-4 \text { toxicities: leukopenia } \\
\text { in } 15 \text { patients }(50 \%) \text {, anorexia in } 4 \\
\text { patients }(13 \%) \text {, hyponatremia in } 3 \\
\text { patients }(10 \%)\end{array}$ \\
\hline Perry (80) & $\begin{array}{l}\text { Prospective, } \\
\text { phase III }\end{array}$ & $\begin{array}{l}\text { Age }>65 \text { yrs, ECOG } \\
0-2, \text { median age } 73\end{array}$ & 562 & $\begin{array}{l}2.67 \text { Gy } \times 15 \text { vs. } 2.67 \text { Gy } \times 15 \\
\text { with concurrent and adjuvant } \\
\text { temozolomide ( } 12 \text { cycles) }\end{array}$ & $\begin{array}{l}7.6 \text { vs. } 9.3 \text {, methylated MGMT: } 7.7 \\
\text { vs. } 13.5(\mathrm{P}=0.001) \text {, unmethylated } \\
\text { MGMT: } 7.9 \text { vs. } 10(\mathrm{P}=0.055) \text {. Grade } \\
\text { 3-4 hematologic toxicity: } 25 \% \text { in } \\
\text { chemoradiation vs. } 9 \% \text { in radiation } \\
\text { alone arm }\end{array}$ \\
\hline
\end{tabular}

KPS, Karnofsky performance status; RPA, recursive partitioning analysis; MGMT, O6-methylguanine-DNA-methyltransferase; PTV, planning target volume.

\section{HRT administered with concurrent and adjuvant chemotherapy}

With Stupp's trial establishing standard of care for GBM treatment, several studies were published to assess the safety and efficacy of postoperative HRT with concurrent and adjuvant TMZ (Table 6). Retrospective and single arm prospective GBM studies suggested promising median OS (12.4 to 15.6 months) with acceptable toxicity and neurocognition (76-78). Ohno et al. recently reported on 30 GBM patients (age $\geq 75$, KPS $\geq 50$ ) treated with either HRT (45 Gy/15 fractions) with concurrent and adjuvant TMZ or a combination of adjuvant TMZ and bevacizumab. The reported median OS, PFS and time for KPS score to decrease below 60 were $12.9,9.9$ and 7.9 months, respectively (79).

A landmark phase III (CE.6) randomized trial compared HRT alone (40 Gy/15 fractions) vs. HRT (40 Gy/15 fractions) with concurrent daily TMZ and adjuvant TMZ for 12 cycles in 562 GBM patients (age $\geq 65$ ) (80). Unlike the Stupp trial, a short course of radiation and concurrent
TMZ were delivered but the number of cycles of adjuvant TMZ was higher. Median age of patients was 73 years. Chemoradiation resulted in a significant improvement in median OS (9.3 vs. 7.6 months, $\mathrm{P}<0.0001)$ and $\mathrm{PFS}$ (5.3 vs. 3.9 months, $\mathrm{P}<0.001$ ). Importantly, this progress was accomplished with acceptable hematologic toxicities. Despite gastrointestinal toxicity being slightly higher in the chemoradiation arm, there was no substantial impact on QoL. Notably, this trial only included patients with ECOG PS-0-2. To date, this regimen has not been directly compared with the standard 6-week radiation regimen with concurrent and adjuvant TMZ in the elderly population.

\section{HRT with chemotherapy versus standard radiotherapy (SRT) with chemotherapy}

There are no randomized trials that have directly compared HRT + TMZ with SRT + TMZ. However, there have been retrospective studies comparing the efficacy and toxicity of the two regimens with mixed results (Table 7). Minniti et al. and Arvold et al. reported no significant differences in 
Table 7 Selected series of hypofractionated radiation (HRT) with temozolomide compared with standard radiation (SRT) with temozolomide

\begin{tabular}{|c|c|c|c|c|c|}
\hline Study & Type & $\begin{array}{l}\text { Patient } \\
\text { selection }\end{array}$ & $\begin{array}{l}\text { No. of } \\
\text { patients }\end{array}$ & Arms & Median survival (months)/toxicity \\
\hline Minniti (81) & Retrospective & $\begin{array}{l}\text { Age } \geq 65 \text { years, } \\
\text { KPS } \geq 60\end{array}$ & 243 & $\begin{array}{l}2 \text { Gy } \times 30 \text { vs. } 2.67 \text { Gy } \times 15 \text {. Both } \\
\text { with concurrent and adjuvant } \\
\text { temozolomide }\end{array}$ & $\begin{array}{l}12 \text { vs. } 12.5 \text {. Higher grade } 2-3 \text { neurologic } \\
\text { toxicity, higher steroid requirement and } \\
\text { lowering of KPS scores in standard arm vs. } \\
\text { hypofractionated arm }\end{array}$ \\
\hline Gzell (83) & Retrospective & Age $65-75$ & 69 & $\begin{array}{l}2 \mathrm{~Gy} \times 30 \text { vs. } 2.67 \mathrm{~Gy} \times 15.70 \% \\
\text { received temozolomide }\end{array}$ & $\begin{array}{l}\text { 12. } 15 \text { (SRT) vs. } 9 \text { (HRT), } 13 \text { (TMZ) vs. } 7 \text { (no } \\
\text { temozolomide) }\end{array}$ \\
\hline $\begin{array}{l}\text { Chang-Halpenny } \\
\text { (84) }\end{array}$ & Retrospective & Age $>65$ & 129 & $\begin{array}{l}2 \text { Gy } \times 30 \text { vs. } 3.5 \text { Gy } \times 10 \text {. Both } \\
\text { with concurrent temozolomide }\end{array}$ & 13 vs. 5.4 \\
\hline
\end{tabular}

KPS, Karnofsky performance status; SRT, standard radiation therapy; HRT, hypofractionated radiation therapy; TMZ, temozolomide.

survival between the two regimens. Of note, patients in the HRT + TMZ arm in the latter review were significantly older and had worse baseline PS $(81,82)$. In contrast, Gzell et al. and Chang-Halpenny et al. have reported worse outcomes with HRT + TMZ compared with SRT + TMZ. Again, patients treated with HRT + TMZ in the latter study had significantly worse prognostic factors at baseline that could be the reason for the observed inferior outcomes $(83,84)$.

\section{Patients with poor performance status}

The patients with poor PS have been largely excluded from trial. Earlier sections have touched upon a few studies that included this subset. Although there is a lack of high-quality evidence, we will attempt to evaluate available treatment options for patients with poor PS. These include radiation with standard fractionation (SRT) alone, hypofractionated radiation (HRT) alone, concurrent chemoradiation with either SRT or HRT, and chemotherapy alone. For patients with KPS $\leq 50$, the benefit in survival as well as PS by radiotherapy (1.5-6 Gy fraction sizes) was shown by Marina and colleagues (85). Similarly, for patients with KPS $\leq 50$, Bauman et al. failed to show a benefit for protracted treatment compared to a shorter palliative course (30 Gy/10 fractions whole brain). However, in this study, the patient groups were not fully balanced at baseline, with significantly older patients receiving the longer radiation course (60).

A logical solution to improve tolerance to therapy for these patients would be sequential delivery of treatment. The Lamborn analysis and NCDP data $(21,86)$ both showed disappointing results although the results of the former study are increasingly dated and the latter one has the drawbacks associated with a database review. Of note, HRT was either not used or not assessed. Mixed results in terms of survival for patients with KPS $<70$ have been reported when combining SRT with concurrent chemotherapy $(87,88)$. However, another study of patients with KPS $<70$ reported promising survival and acceptable toxicity with HRT and concurrent TMZ (89). Improved efficacy was also reported by TMZ alone $v s$. BSC for patients with KPS $<70$ (90).

Finally, a prospective study of patients (median KPS 70) reported similar survival for a 60 Gy 6-week and 40-Gy 3 -week course with less steroid dependency associated with HRT (68). The same group then showed equivalence in survival and QoL between 25 Gy/5 fractions and 40 Gy/15 fractions for elderly and/or frail patients (91).

\section{RT target volume delineation}

Variation in target volume design exists for both standard and HRT. RTOG uses a 2-phase approach, with an initial phase targeting edema (T2/FLAIR hyperintense), gross residual tumor (T1-enhancing) and surgical cavity followed by a boost to the gross tumor and cavity. This is in contrast to EORTC single-phase approach, directed at enhancing tumor plus cavity with a wide margin (without specifically targeting edema) for the entire treatment (26). Retrospective studies suggest small $5 \mathrm{~mm}$ clinical target volume (CTV) margins may not exacerbate the risk of marginal failure. Majority of these plans had 3-5 mm planning target volume (PTV) margin (92). Table 8 summarizes the margins used in cooperative group in clinical trials as well as hypofractionated series.

Although edema is thought to reflect infiltrative 
Table 8 Target volume definitions utilized by various cooperative groups and series

\begin{tabular}{|c|c|c|c|c|}
\hline Cooperative groups & One/two phase & CTV (initial) & CTV (boost) & PTV \\
\hline EORTC (26) & One-phase: 60 Gy in 30 fractions & $\begin{array}{l}\text { Cavity + T1E } \\
+20-30 \mathrm{~mm}\end{array}$ & - & $\begin{array}{l}\text { Institution specific, } \\
\text { generally } 5-7 \mathrm{~mm}\end{array}$ \\
\hline Alliance (93) & Two-phase: $50+10=60$ Gy & $\begin{array}{l}\mathrm{T} 2+\mathrm{T} 1 \mathrm{E}+\text { cavity } \\
+20 \mathrm{~mm} \text { to block } \\
\text { edge }\end{array}$ & $\begin{array}{l}\text { Cavity }+\mathrm{T} 1 \mathrm{E} \\
+20 \mathrm{~mm} \text { to block } \\
\text { edge }\end{array}$ & $\begin{array}{l}\text { PTV addressed in } \\
\text { CTV expansions }\end{array}$ \\
\hline NRG (94) & Two-phase: $46+14=60$ Gy & $\begin{array}{l}\text { T2 + T1E + cavity } \\
+20 \mathrm{~mm}\end{array}$ & $\begin{array}{l}\text { Cavity + T1E } \\
+20 \mathrm{~mm}\end{array}$ & $3-5 \mathrm{~mm}$ \\
\hline Nordic Clinical Brain Tumor Study Group (54) & One-phase: 34 Gy in 10 fractions & $\mathrm{T} 1 \mathrm{E}+2 \mathrm{~cm}^{\star}$ & Not applicable & Institution specific ${ }^{\star}$ \\
\hline Ohno et al. (79) & Two-phase: $30+15=45$ Gy & $\begin{array}{l}\mathrm{T} 2+\mathrm{T} 1 \mathrm{E}+\text { cavity } \\
+15 \mathrm{~mm}\end{array}$ & $\begin{array}{l}\text { Cavity + T1E } \\
+15 \mathrm{~mm}\end{array}$ & $5 \mathrm{~mm}$ \\
\hline
\end{tabular}

*Per Thomas 1994. T1E, residual T1-enhancing abnormality; GTV, gross target volume; CTV, clinical target volume; PTV, planning target volume.

tumor (95), similar patterns of failure are reported with both approaches (96). Ninety percent patients failed centrally and in-field in both treatment plans. CTV delineation based on a $2-\mathrm{cm}$ margin around contrast-enhanced residual tumor and surgical cavity rather than on peritumoral edema did not seem to alter the central pattern of failure (96). Similar patterns were observed in another study that included concurrent and adjuvant TMZ. Central/ in-field and outside-field recurrences occurred in $91 \%$ and $5.4 \%$ of unmethylated patients, and $64 \%$ and $31 \%$ of methylated patients, respectively $(\mathrm{P}=0.01)$. Central recurrence within high dose region predominates regardless of target volume design. The median volume of brain receiving high dose radiation was significantly smaller for plans based on residual tumor and cavity plus $2 \mathrm{~cm}$ $(\mathrm{P}=0.0001)$ (97).

The incidence of neurotoxicity is dependent on the volume of brain parenchyma-a late-responding tissueirradiated to a high dose. If HRT is used to treat GBM, the potential for major acute (edema) and late complications (necrosis and damage to optic chiasm and brainstem) has to be considered, especially when conformal radiotherapy techniques are not used or available. Based on the data available in the literature, it seems to be appropriate to use a $2 \mathrm{~cm}$ margin around residual tumor and cavity as the CTV.

\section{Other modalities}

Besides surgery, radiation and TMZ, other therapies may play a role in palliative treatment of HGG patients with poor prognosis. Some have failed while others are still being investigated. ARTE, a phase II trial, randomized 75 GBM patients (age $\geq 65 \mathrm{yrs}$ ) to HRT (40 Gy/15 fractions) alone or HRT (40 Gy/15 fractions) with bevacizumab. With a median OS of 12 months in both arms, the addition of bevacizumab did not improve survival (98). Another nonrandomized trial by EORTC Brain Tumor Group is actively accruing elderly GBM or AA patients (age $>65$, KPS $\geq 60$ ) and will be evaluating outcomes for the combination of novel multikinase inhibitor TG02 with either TMZ or HRT (39.9 Gy/15 fractions) (99).

Tumor-treating fields (TTF) is used for the treatment of newly diagnosed and recurrent GBM. It is an FDAapproved device consisting of a set of insulated electrodes that must be placed over a shaved scalp. The electrodes create very low intensity alternating electrical fields that 
are thought to selectively target proliferating cells through antimitotic mechanisms. For upfront GBM treatment, TTF starts with adjuvant TMZ phase. The EF14 trial for newly diagnosed GBM enrolled patients with an age range from 20 through 83 (median age $=57$ years), although age-specific outcomes have not been published to date (100). TTF can be considered as a potential treatment option regardless of age but the patient's KPS and estimated survival should determine the appropriateness of its use given the associated cost, treatment duration, and psychosocial factors.

\section{Summary}

The concept of radical/curative $v s$. palliative radiation can be blurred in the management of HGG (including GBM) patients as they are seldom cured. There is a lack of granularity within our current repertoire of how we describe radiation treatment intent: curative versus palliative. In medical oncology, there are other terms including life prolonging therapy, which may be more akin to how we approach HGG treatment.

The current standard of care treatment for HGG with standard fractionation radiation course still provides the best though suboptimal outcomes for the better prognosis patients (Table 2). In patients with shorter expected survival due to poor prognosis (Table 2), radiation with standard fractionation is unlikely to provide a meaningful benefit and a hypofractionated course of RT delivering a much lower BED yields similar survival as shown by studies mentioned earlier.

In this review, the concept of palliative radiation for a patient is based on the estimated poor survival of the patient. Thus, a less intensive and better tolerated course of radiation (hypofractionated radiation) delivering a less than radical dose to such a patient is regarded as palliative radiation. In fact, one can argue that even radiation with standard fractionation is palliative in such a patient with poor prognosis but will do more harm as it is worse tolerated, and the patient will be spending a bigger proportion of his/ her remaining time getting treatment. As many of us may believe we are prolonging survival but not necessarily curing patients, we are selecting a radiation dose/fractionation that is tailored to expected life expectancy. We also acknowledge that palliative is not solely defined by using a hypofractionated regimen. However, our review essentially focuses on the evidence behind alternate dose/fractionation schemes for patients with poorer life expectancy/performance status.
Although one can argue that any radiotherapy in HGG or more specifically GBM, is palliative, but for the sake of simplicity, we are referring to only hypofractionated regimens as palliative. Typically, upfront palliative treatment is offered to patients with poor prognosis. There has been no clear standard of care for the treatment of HGG in patients with poor prognosis for the following reasons: (I) lack of data as these patients were largely excluded from trials, (II) multiple factors (Table 2) affecting prognosis and their interactions with each other, (III) traditional caveats associated with retrospective reviews, (IV) lack of clear definition of prognostic factors and their subjective interpretation and $(\mathrm{V})$ differences in tumor biology.

The outcomes from surgical studies favor maximal safe resection, regardless of age. However, these studies provide limited data related to potential surgical complications, neurocognitive status and time to functional recovery after varying levels of resections. With such an aggressive disease, maintaining QoL and preventing new permanent neurological deficits are important factors to consider before embarking on a surgical plan for these patients. Optimal surgery can have a dramatic effect on a patient's functional status which subsequently alters their KPS score. This improvement in post-operative KPS has been associated with increased OS and has superior predictive value compared to pre-operative KPS score (101). In absence of randomized studies, the optimal surgical management in these patients should be based on careful evaluation of metrics such as neurologic and geriatric assessment, speed of clinical decline, operative risk and estimation of prognosis.

Although SRT may represent a viable treatment option for select elderly fit patients (age 60-70), results of phase III studies comparing SRT and HRT regimens demonstrate benefit in terms of similar survival and decreased treatment duration with HRT. The toxicity of hypofractionation must, however, be considered. With conservative margins and advanced radiation techniques routinely employed in practice, conformal and precise radiation doses to the target can be delivered while risk of neurocognitive decline is lowered with reduced exposure of the adjacent normal brain parenchyma.

The assessment of neurocognitive and functional status and maintenance of QoL is of particular relevance to ensure optimal outcomes. Studies have shown no significant worsening of neurocognition and QoL with radiation. McAleese et al. reported improvement or stability in Barthel scores of $68 \%$ patients with $30 \mathrm{~Gy} / 6$ fraction regimen (57). 
In a trial comparing SRT versus HRT, KPS scores were not significantly different between groups (68). Moreover, the HRT resulted in decreased corticosteroid requirement. Notably, 26\% of patients receiving SRT vs. $10 \%$ receiving HRT had treatment interruptions due to acute toxicity. There was no significant change in global health status and functioning scales between SRT and HRT in the Nordic study. However, cautious interpretation is required due to low completion rates of these QoL questionnaires (71). Similar mean global QoL scores at 8 weeks were reported by both $40 \mathrm{~Gy} / 15$ fractions and $25 \mathrm{~Gy} / 5$ fractions regimens (69).

In terms of chemotherapy, TMZ is an efficacious and tolerated treatment for elderly GBM patients. It is correlated with significant improvement in KPS, neurocognitive evaluation and QoL questionnaires. However, approximately $20 \%$ patients experience grade 3-4 hematologic toxicity. TMZ, compared with SRT, results in improved survival in elderly patients with MGMT methylated tumors. The benefit from TMZ is most prominent in GBM patients with methylated MGMT promoter. The outcomes of the NOA-08 and Nordic trials support consideration of TMZ alone for MGMT methylated, elderly patients, especially if radiation delivery is impractical or contraindicated (70). Furthermore, chemotherapy alone, as compared to radiation, has the benefit of requiring less frequent and fewer total trips to a medical provider.

Although SRT with concurrent and adjuvant TMZ is a reasonable option in patients with good PS and under the age of 70, concerns remain about the length of treatment as well as PS and under the age of 70, treatment-related neurotoxicity resulting in worsening of QoL and functional status remains a concern. Based on the results of the CE.6 trial, elderly patients with MGMT promoter methylation should be offered HRT with concurrent and adjuvant TMZ. Although MGMT methylation is highly predictive for benefit from $T M Z$, interpretation of this benefit in the case of MGMT-unmethylated tumors remains controversial, with recent evidence indicating some benefit from combined-modality treatment $(80,102)$. There was no reduction in benefit from $T M Z$ with increasing age. The survival advantage of TMZ was conferred without a sacrifice in QoL and with manageable toxicity. Many may favor the hypofractionated protocol in context of these results and an EORTC subgroup analysis failing to show survival benefit with standard chemoradiation in patients over the age of 65 $(\mathrm{P}=0.340)$ (103).

Patients deemed unfit for chemoradiation should be treated with HRT or TMZ based on MGMT promoter methylation status. These patients are treated with HRT especially for tumors without MGMT methylation or unknown promoter status. The HRT regimen of $34 \mathrm{~Gy} / 10$ fractions or $40 \mathrm{~Gy} / 15$ fractions are most commonly employed, but an attractive alternative is 25 Gy/5 fractions, particularly in terms of treatment duration, intolerance to concurrent chemotherapy and completion in less than a week (69). This further hypofractionation does not seem to compromise survival but has a potential to cause neurocognitive side effects which will assume more relevance once other treatment options allow long-term survival in elderly GBM patients.

In selecting patients for combined modality therapy (CMT), the importance of assessing the patient's performance status is crucial. Some studies have highlighted the significance of PS as being the most relevant factor for selecting patients for CMT $(73,74)$. CE.6 included elderly patients but only with PS 0-1 (80). With the lack of data, the decision to embark on a specific treatment option needs to be taken while considering not only PS and age but other prognostic factors as mentioned earlier.

Currently, there are two nomograms available to assist in treatment decision making by individualizing cancer prognosis in GBM. Both are, however, based on standard fractionation radiotherapy. The first is an internally and externally validated nomogram developed by using data from NRG Oncology trials, 0525 and 0825 . Increasing age, male gender, lower KPS, sub-total resection, and unmethylated MGMT status were associated with poor survival (104). However, it did not include important prognostic factors, such as receipt of concurrent chemoradiation and IDH mutation status. Gittleman et al. then developed a nomogram for IDH-wt GBM and found that younger age, female sex, gross total resection, concurrent radiation/TMZ, high KPS and MGMT methylation were associated with better survival (31).

Based on our review of the literature, we make the following recommendations for HGG treatment (Table 9):

(I) Age $<65$, KPS $\geq 60$, expected median survival $>6-8$ months: consider standard radiation with concurrent and adjuvant TMZ and alternating electric field therapy.

(II) Age $\geq 65$, KPS $\geq 60$, expected median survival >6-8 months, MGMT promoter methylated: consider standard radiation with concurrent and adjuvant TMZ and alternating electric field therapy or hypofractionated radiation with 
Table 9 Recommendations for treatment of high-grade glioma (HGG)

\begin{tabular}{lllll}
\hline $\begin{array}{l}\text { Age } \\
\text { (years) }\end{array}$ & $\begin{array}{l}\text { KPS } \\
{[1-100]}\end{array}$ & $\begin{array}{l}\text { Expected } \\
\text { survival (months) }\end{array}$ & $\begin{array}{l}\text { MGMT promoter } \\
\text { methylation status }\end{array}$ & Management \\
\hline$<65$ & $\geq 60$ & $>6-8$ & & SRT + concurrent \& adjuvant TMZ + EFT \\
$\geq 65$ & $\geq 60$ & $>6-8$ & Positive & SRT + concurrent \& adjuvant TMZ + EFT or HRT + concurrent \& adjuvant TMZ \\
$\geq 65$ & $\geq 60$ & $>6-8$ & Negative or unknown & SRT + concurrent \& adjuvant TMZ + EFT. HRT + concurrent \& adjuvant TMZ is \\
& & & an option \\
$\geq 65$ & $\geq 60$ & $<6-8$ & Positive & HRT + concurrent \& adjuvant TMZ \\
$\geq 65$ & $\geq 60$ & $<6-8$ & Negative or unknown & HRT + concurrent \& adjuvant TMZ or HRT alone \\
$\geq 65$ & $<60$ & $<6-8$ & Negative or unknown & HRT alone \\
$\geq 65$ & $<60$ & $<6-8$ & Positive & TMZ alone \\
$<65$ & $<60$ & $>6-8$ & & HRT +/- concurrent \& adjuvant TMZ \\
$<65$ & $<60$ & $<6-8$ & & HRT alone or TMZ alone \\
\hline
\end{tabular}

SRT, standard radiation therapy; HRT, hypofractionated radiation therapy; TMZ, temozolomide; EFT, electric field therapy.

concurrent and adjuvant TMZ.

(III) Age $\geq 65$, KPS $\geq 60$, expected median survival $>6-8$ months, MGMT promoter unmethylated/ unknown: consider standard radiation with concurrent and adjuvant TMZ and alternating electric field therapy. Hypofractionated radiation with concurrent and adjuvant $\mathrm{TMZ}$ is an option.

(IV) Age $\geq 65$, KPS $\geq 60$, expected median survival $<6-8$ months, MGMT promoter methylated: consider hypofractionated radiation with concurrent and adjuvant TMZ.

(V) Age $\geq 65$, KPS $\geq 60$, expected median survival $<6-8$ months, MGMT promoter unmethylated/ unknown: consider hypofractionated radiation with concurrent and adjuvant TMZ or HRT alone.

(VI) Age $\geq 65$, KPS $<60$, expected median survival $<6-8$ months, MGMT promoter unmethylated/ unknown: consider HRT alone.

(VII) Age $\geq 65$, KPS $<60$, expected median survival $<6-8$ months, MGMT promoter-methylated: consider TMZ monotherapy.

(VIII) Age $<65$, KPS $<60$, expected median survival $>6-8$ months: consider HRT +/- concurrent or adjuvant TMZ.

(IX) Age $<65$, KPS $<60$, expected median survival $<6-8$ months: consider HRT alone or TMZ alone.

Current NCCN guidelines (V2.2020) recommend HRT with the optional addition of concurrent or adjuvant TMZ for GBM patients with KPS $<60$ and age $\leq 70$ and HRT or TMZ alone for KPS $<60$ and age $>70$. The addition of TMZ to HRT/SRT (methylated) and TMZ to SRT (unmethylated) becomes a category 1 recommendation for patients with KPS $\geq 60$ and age $>70$. The American Society for Radiation Oncology's (ASTRO) practice guidelines [endorsed by American Society of Clinical Oncology's (ASCO)] from 2016 recommend HRT alone, TMZ alone or BSC for poor performance status (KPS $<60$ ) patients and consideration for RT with concurrent and adjuvant $\mathrm{TMZ}$ in patients (age $\geq 70$ years) with KPS $\geq 50$ (105).

\section{Future directions}

It is important that further research continues to explore the biology and development of individualized protocols for optimal management of HGG. Future trial designs should include primary end points to evaluate the tolerance of various therapeutic modalities, potential impact on QoL with TMZ vs. HRT alone and striving for an acceptable non-inferiority margin in OS as a tradeoff for shorter time on treatment.

An area of active research includes the use of appropriate radiation response modulators. The final results of a UK study of elderly HGG patients (NCT01602588) assessing the addition of hydroxychloroquine to radiation (30 Gy/5 fractions) are eagerly awaited (106). With a deeper understanding of the biology of HGG and well-designed trials, the hope is to personalize and optimize palliative treatment for advanced patient care. 


\section{Acknowledgments}

Funding: None.

\section{Footnote}

Provenance and Peer Review: This article was commissioned by the Guest Editors (Jerome Graber, Hany Soliman) for the series "Palliative Care in Neuro-Oncology" published in Annals of Palliative Medicine. The article has undergone external peer review.

Reporting Checklist: The authors have completed the Narrative Review reporting checklist. Available at http:// dx.doi.org/10.21037/apm-20-1246

Peer Review File: Available at http://dx.doi.org/10.21037/ apm-20-1246

Conflicts of Interest: All authors have completed the ICMJE uniform disclosure form (available at http://dx.doi. org/10.21037/apm-20-1246). The series "Palliative Care in Neuro-Oncology" was commissioned by the editorial office without any funding or sponsorship. YDT serves as an unpaid editorial board member of Annals of Palliative Medicine from May 2019 to Apr 2021. SSL serves as an unpaid Associate Editors-in-Chief of Annals of Palliative Medicine from Dec 2019 to Nov 2021. SSL reports to have relationships with Elekta $\mathrm{AB}$, Member of Gamma Knife ICON Expert Group. The authors have no other conflicts of interest to declare.

Ethical Statement: The authors are accountable for all aspects of the work in ensuring that questions related to the accuracy or integrity of any part of the work are appropriately investigated and resolved.

Open Access Statement: This is an Open Access article distributed in accordance with the Creative Commons Attribution-NonCommercial-NoDerivs 4.0 International License (CC BY-NC-ND 4.0), which permits the noncommercial replication and distribution of the article with the strict proviso that no changes or edits are made and the original work is properly cited (including links to both the formal publication through the relevant DOI and the license). See: https://creativecommons.org/licenses/by-nc-nd/4.0/.

\section{References}

1. Mesfin FB, Al-Dhahir MA. Cancer, Brain Gliomas. StatPearls. Treasure Island (FL): StatPearls Publishing Copyright (C) 2020, StatPearls Publishing LLC.; 2020.

2. Ostrom QT, Gittleman H, Truitt G, et al. CBTRUS Statistical Report: Primary Brain and Other Central Nervous System Tumors Diagnosed in the United States in 2011-2015. Neuro Oncol 2018;20:iv1-86.

3. Clarke JW, Chang EL, Levin VA, et al. Optimizing radiotherapy schedules for elderly glioblastoma multiforme patients. Expert Rev Anticancer Ther 2008;8:733-41.

4. Young JS, Chmura SJ, Wainwright DA, et al. Management of glioblastoma in elderly patients. J Neurol Sci 2017;380:250-5.

5. Tsang DS, Khan L, Perry JR, et al. Survival outcomes in elderly patients with glioblastoma. Clin Oncol (R Coll Radiol) 2015;27:176-83.

6. Ladomersky E, Scholtens DM, Kocherginsky M, et al. The Coincidence Between Increasing Age, Immunosuppression, and the Incidence of Patients With Glioblastoma. Front Pharmacol 2019;10:200.

7. Bauchet L, Zouaoui S, Darlix A, et al. Assessment and treatment relevance in elderly glioblastoma patients. Neuro Oncol 2014;16:1459-68.

8. Wen PY, Kesari S. Malignant gliomas in adults. N Engl J Med 2008;359:492-507.

9. Ostrom QT, Gittleman H, Farah P, et al. CBTRUS statistical report: Primary brain and central nervous system tumors diagnosed in the United States in 2006-2010. Neuro Oncol 2013;15 Suppl 2:ii1-56.

10. Ohgaki H, Kleihues P. Genetic pathways to primary and secondary glioblastoma. Am J Pathol 2007;170:1445-53.

11. Nobusawa S, Watanabe T, Kleihues P, et al. IDH1 mutations as molecular signature and predictive factor of secondary glioblastomas. Clin Cancer Res 2009;15:6002-7.

12. Yan H, Parsons DW, Jin G, et al. IDH1 and IDH2 mutations in gliomas. N Engl J Med 2009;360:765-73.

13. Jiang H, Cui Y, Wang J, et al. Impact of epidemiological characteristics of supratentorial gliomas in adults brought about by the 2016 world health organization classification of tumors of the central nervous system. Neurosurg Clin N Am 2019;30:35-42.

14. Glioblastoma and Malignant Astrocytoma. In: American Brain Tumor Association. Available online: https://www. abta.org/wp-content/uploads/2018/03/glioblastoma- 
brochure.pdf. Accessed 05/10/2020.

15. Hartmann C, Meyer J, Balss J, et al. Type and frequency of IDH1 and IDH2 mutations are related to astrocytic and oligodendroglial differentiation and age: a study of 1,010 diffuse gliomas. Acta Neuropathol 2009;118:469-74.

16. Tamimi AF, Juweid M. Epidemiology and Outcome of Glioblastoma. In: De Vleeschouwer S, editor. Glioblastoma. Brisbane (AU): Codon Publications Copyright: The Authors.; 2017.

17. Grimm SA, Chamberlain MC. Anaplastic astrocytoma. CNS Oncol 2016;5:145-57.

18. Rahman R, Catalano PJ, Reardon DA, et al. Incidence, risk factors, and reasons for hospitalization among glioblastoma patients receiving chemoradiation. J Neurooncol 2015;124:137-46.

19. Schag CC, Heinrich RL, Ganz PA. Karnofsky performance status revisited: reliability, validity, and guidelines. J Clin Oncol 1984;2:187-93.

20. Scott JG, Bauchet L, Fraum TJ, et al. Recursive partitioning analysis of prognostic factors for glioblastoma patients aged 70 years or older. Cancer 2012;118:5595-600.

21. Lamborn KR, Chang SM, Prados MD. Prognostic factors for survival of patients with glioblastoma: recursive partitioning analysis. Neuro Oncol 2004;6:227-35.

22. Buckner JC. Factors influencing survival in high-grade gliomas. Semin Oncol 2003;30:10-4.

23. Kita D, Ciernik IF, Vaccarella S, et al. Age as a predictive factor in glioblastomas: population-based study. Neuroepidemiology 2009;33:17-22.

24. Kanu OO, Mehta A, Di C, et al. Glioblastoma multiforme: a review of therapeutic targets. Expert Opin Ther Targets 2009;13:701-18.

25. Curran WJ, Jr., Scott CB, Horton J, et al. Recursive partitioning analysis of prognostic factors in three Radiation Therapy Oncology Group malignant glioma trials. J Natl Cancer Inst 1993;85:704-10.

26. Stupp R, Mason WP, van den Bent MJ, et al. Radiotherapy plus concomitant and adjuvant temozolomide for glioblastoma. N Engl J Med 2005;352:987-96.

27. Sheline GE. Radiotherapy for high grade gliomas. Int J Radiat Oncol Biol Phys 1990;18:793-803.

28. Pollack IF, Hamilton RL, Sobol RW, et al. IDH1 mutations are common in malignant gliomas arising in adolescents: a report from the Children's Oncology Group. Childs Nerv Syst 2011;27:87-94.

29. Watanabe T, Nobusawa S, Kleihues P, et al. IDH1 mutations are early events in the development of astrocytomas and oligodendrogliomas. Am J Pathol 2009;174:1149-53.

30. Ladomersky E, Zhai L, Gritsina G, et al. Advanced age negatively impacts survival in an experimental brain tumor model. Neurosci Lett 2016;630:203-8.

31. Gittleman H, Cioffi G, Chunduru P, et al. An independently validated nomogram for isocitrate dehydrogenase-wild-type glioblastoma patient survival. Neurooncol Adv 2019;1:vdz007.

32. Lukas RV, Mrugala MM. Pivotal therapeutic trials for infiltrating gliomas and how they affect clinical practice. Neurooncol Pract 2017;4:209-19.

33. Herrlinger U, Tzaridis T, Mack F, et al. Lomustinetemozolomide combination therapy versus standard temozolomide therapy in patients with newly diagnosed glioblastoma with methylated MGMT promoter (CeTeG/ NOA-09): a randomised, open-label, phase 3 trial. Lancet 2019;393:678-88.

34. Laperriere N, Weller M, Stupp R, et al. Optimal management of elderly patients with glioblastoma. Cancer Treat Rev 2013;39:350-7.

35. Arvold ND, Reardon DA. Treatment options and outcomes for glioblastoma in the elderly patient. Clin Interv Aging 2014;9:357-67.

36. Westphal M, Hilt DC, Bortey E, et al. A phase 3 trial of local chemotherapy with biodegradable carmustine (BCNU) wafers (Gliadel wafers) in patients with primary malignant glioma. Neuro Oncol 2003;5:79-88.

37. Jayani R, Hurria A. Caregivers of older adults with cancer. Semin Oncol Nurs 2012;28:221-5.

38. Boele FW, Given CW, Given BA, et al. Family caregivers' level of mastery predicts survival of patients with glioblastoma: A preliminary report. Cancer 2017;123:832-40.

39. Noorbakhsh A, Tang JA, Marcus LP, et al. Grosstotal resection outcomes in an elderly population with glioblastoma: a SEER-based analysis. J Neurosurg 2014;120:31-9.

40. Hoffermann M, Bruckmann L, Kariem Mahdy A, et al. Treatment results and outcome in elderly patients with glioblastoma multiforme--a retrospective single institution analysis. Clin Neurol Neurosurg 2015;128:60-9.

41. Almenawer SA, Badhiwala JH, Alhazzani W, et al. Biopsy versus partial versus gross total resection in older patients with high-grade glioma: a systematic review and metaanalysis. Neuro Oncol 2015;17:868-81.

42. Zou Y, Bai HX, Wang Z, et al. Biopsy versus resection in the management of high-grade gliomas in the elderly. 
Neuro Oncol 2015;17:901-3.

43. Vuorinen V, Hinkka S, Färkkilä M, et al. Debulking or biopsy of malignant glioma in elderly people - a randomised study. Acta Neurochir (Wien) 2003;145:5-10.

44. D'Amico FE, Ruffolo C, Romano M, et al. Rare Neoplasm Mimicking Neuoroendocrine Pancreatic Tumor: A Case Report of Solitary Fibrous Tumor with Review of the Literature. Anticancer Res 2017;37:3093-7.

45. Oszvald A, Güresir E, Setzer M, et al. Glioblastoma therapy in the elderly and the importance of the extent of resection regardless of age. J Neurosurg 2012;116:357-64.

46. Babu R, Komisarow JM, Agarwal VJ, et al. Glioblastoma in the elderly: the effect of aggressive and modern therapies on survival. J Neurosurg 2016;124:998-1007.

47. Chaichana KL, Garzon-Muvdi T, Parker S, et al. Supratentorial glioblastoma multiforme: the role of surgical resection versus biopsy among older patients. Ann Surg Oncol 2011;18:239-45.

48. Walker MD, Alexander E Jr, Hunt WE, et al. Evaluation of BCNU and/or radiotherapy in the treatment of anaplastic gliomas. A cooperative clinical trial. J Neurosurg 1978;49:333-43.

49. Walker MD, Strike TA, Sheline GE. An analysis of doseeffect relationship in the radiotherapy of malignant gliomas. Int J Radiat Oncol Biol Phys 1979;5:1725-31.

50. Bleehen NM, Stenning SP. A Medical Research Council trial of two radiotherapy doses in the treatment of grades 3 and 4 astrocytoma. The Medical Research Council Brain Tumour Working Party. Br J Cancer 1991;64:769-74.

51. Paszat L, Laperriere N, Groome P, et al. A populationbased study of glioblastoma multiforme. Int J Radiat Oncol Biol Phys 2001;51:100-7.

52. Keime-Guibert F, Chinot O, Taillandier L, et al. Radiotherapy for glioblastoma in the elderly. N Engl J Med 2007;356:1527-35.

53. Halperin EC. Malignant gliomas in older adults with poor prognostic signs. Getting nowhere, and taking a long time to do it. Oncology (Williston Park) 1995;9:229-34; discussion 237-8, 243.

54. Thomas R, James N, Guerrero D, et al. Hypofractionated radiotherapy as palliative treatment in poor prognosis patients with high grade glioma. Radiother Oncol 1994;33:113-6.

55. Kleinberg L, Slick T, Enger C, et al. Short course radiotherapy is an appropriate option for most malignant glioma patients. Int J Radiat Oncol Biol Phys 1997;38:31-6.

56. Chang EL, Yi W, Allen PK, et al. Hypofractionated radiotherapy for elderly or younger low-performance status glioblastoma patients: outcome and prognostic factors. Int J Radiat Oncol Biol Phys 2003;56:519-28.

57. McAleese JJ, Stenning SP, Ashley S, et al. Hypofractionated radiotherapy for poor prognosis malignant glioma: matched pair survival analysis with MRC controls. Radiother Oncol 2003;67:177-82.

58. Lutterbach J, Ostertag C. What is the appropriate radiotherapy protocol for older patients with newly diagnosed glioblastoma? J Clin Oncol 2005;23:2869-70.

59. Hernandez JC, Maruyama Y, Yaes R, et al. Accelerated fractionation radiotherapy for hospitalized glioblastoma multiforme patients with poor prognostic factors. J Neurooncol 1990;9:41-5.

60. Bauman GS, Gaspar LE, Fisher BJ, et al. A prospective study of short-course radiotherapy in poor prognosis glioblastoma multiforme. Int J Radiat Oncol Biol Phys 1994;29:835-9.

61. Slotman BJ, Kralendonk JH, van Alphen HA, et al. Hypofractionated radiation therapy in patients with glioblastoma multiforme: results of treatment and impact of prognostic factors. Int J Radiat Oncol Biol Phys 1996;34:895-8.

62. Ford JM, Stenning SP, Boote DJ, et al. A short fractionation radiotherapy treatment for poor prognosis patients with high grade glioma. Clin Oncol (R Coll Radiol) 1997;9:20-4.

63. Hulshof MC, Schimmel EC, Andries Bosch D, et al. Hypofractionation in glioblastoma multiforme. Radiother Oncol 2000;54:143-8.

64. Sultanem K, Patrocinio H, Lambert C, et al. The use of hypofractionated intensity-modulated irradiation in the treatment of glioblastoma multiforme: preliminary results of a prospective trial. Int J Radiat Oncol Biol Phys 2004;58:247-52.

65. Floyd NS, Woo SY, Teh BS, et al. Hypofractionated intensity-modulated radiotherapy for primary glioblastoma multiforme. Int J Radiat Oncol Biol Phys 2004;58:721-6.

66. Gliński B. Postoperative hypofractionated radiotherapy versus conventionally fractionated radiotherapy in malignant gliomas. A preliminary report on a randomized trial. J Neurooncol 1993;16:167-72.

67. Phillips C, Guiney M, Smith J, et al. A randomized trial comparing 35Gy in ten fractions with 60Gy in 30 fractions of cerebral irradiation for glioblastoma multiforme and older patients with anaplastic astrocytoma. Radiother Oncol 2003;68:23-6.

68. Roa W, Brasher PM, Bauman G, et al. Abbreviated course 
of radiation therapy in older patients with glioblastoma multiforme: a prospective randomized clinical trial. J Clin Oncol 2004;22:1583-8.

69. Roa W, Kepka L, Kumar N, et al. International Atomic Energy Agency Randomized Phase III Study of Radiation Therapy in Elderly and/or Frail Patients With Newly Diagnosed Glioblastoma Multiforme. J Clin Oncol 2015;33:4145-50.

70. Wick W, Platten M, Meisner C, et al. Temozolomide chemotherapy alone versus radiotherapy alone for malignant astrocytoma in the elderly: the NOA-08 randomised, phase 3 trial. Lancet Oncol 2012;13:707-15.

71. Malmström A, Grønberg BH, Marosi C, et al.

Temozolomide versus standard 6-week radiotherapy versus hypofractionated radiotherapy in patients older than 60 years with glioblastoma: the Nordic randomised, phase 3 trial. Lancet Oncol 2012;13:916-26.

72. Hegi ME, Diserens AC, Gorlia T, et al. MGMT gene silencing and benefit from temozolomide in glioblastoma. N Engl J Med 2005;352:997-1003.

73. Minniti G, De Sanctis V, Muni R, et al. Hypofractionated radiotherapy followed by adjuvant chemotherapy with temozolomide in elderly patients with glioblastoma. J Neurooncol 2009;91:95-100.

74. Muni R, Minniti G, Lanzetta G, et al. Short-term radiotherapy followed by adjuvant chemotherapy in poor-prognosis patients with glioblastoma. Tumori 2010;96:60-4.

75. Lim YJ, Kim IH, Han TJ, et al. Hypofractionated chemoradiotherapy with temozolomide as a treatment option for glioblastoma patients with poor prognostic features. Int J Clin Oncol 2015;20:21-8.

76. Panet-Raymond V, Souhami L, Roberge D, et al. Accelerated hypofractionated intensity-modulated radiotherapy with concurrent and adjuvant temozolomide for patients with glioblastoma multiforme: a safety and efficacy analysis. Int J Radiat Oncol Biol Phys 2009;73:473-8.

77. Terasaki M, Eto T, Nakashima S, et al. A pilot study of hypofractionated radiation therapy with temozolomide for adults with glioblastoma multiforme. J Neurooncol 2011;102:247-53.

78. Minniti G, Lanzetta G, Scaringi C, et al. Phase II study of short-course radiotherapy plus concomitant and adjuvant temozolomide in elderly patients with glioblastoma. Int J Radiat Oncol Biol Phys 2012;83:93-9.

79. Ohno M, Miyakita Y, Takahashi M, et al. Survival benefits of hypofractionated radiotherapy combined with temozolomide or temozolomide plus bevacizumab in elderly patients with glioblastoma aged $\geq 75$ years. Radiat Oncol 2019;14:200.

80. Perry JR, Laperriere N, O'Callaghan CJ, et al. ShortCourse Radiation plus Temozolomide in Elderly Patients with Glioblastoma. N Engl J Med 2017;376:1027-37.

81. Minniti G, Scaringi C, Lanzetta G, et al. Standard (60 Gy) or short-course (40 Gy) irradiation plus concomitant and adjuvant temozolomide for elderly patients with glioblastoma: a propensity-matched analysis. Int J Radiat Oncol Biol Phys 2015;91:109-15.

82. Arvold ND, Tanguturi SK, Aizer AA, et al. Hypofractionated versus standard radiation therapy with or without temozolomide for older glioblastoma patients. Int J Radiat Oncol Biol Phys 2015;92:384-9.

83. Gzell C, Wheeler H, Guo L, et al. Elderly patients aged 65-75 years with glioblastoma multiforme may benefit from long course radiation therapy with temozolomide. J Neurooncol 2014;119:187-96.

84. Chang-Halpenny CN, Yeh J, Lien WW. Elderly patients with glioblastoma multiforme treated with concurrent temozolomide and standard- versus abbreviated-course radiotherapy. Perm J 2015;19:15-20.

85. Marina O, Suh JH, Reddy CA, et al. Treatment outcomes for patients with glioblastoma multiforme and a low Karnofsky Performance Scale score on presentation to a tertiary care institution. Clinical article. J Neurosurg 2011;115:220-9.

86. Parr E, Sleightholm RL, Baine MJ, et al. Efficacy of sequential radiation and chemotherapy in treating glioblastoma with poor performance status. J Neurooncol 2020;147:91-5.

87. Combs SE, Wagner J, Bischof M, et al. Postoperative treatment of primary glioblastoma multiforme with radiation and concomitant temozolomide in elderly patients. Int J Radiat Oncol Biol Phys 2008;70:987-92.

88. Niyazi M, Schwarz SB, Suchorska B, et al. Radiotherapy with and without temozolomide in elderly patients with glioblastoma. Strahlenther Onkol 2012;188:154-9.

89. Reyngold M, Lassman AB, Chan TA, et al. Abbreviated course of radiation therapy with concurrent temozolomide for high-grade glioma in patients of advanced age or poor functional status. J Neurooncol 2012;110:369-74.

90. Liu YL, Liu PF, Shao W, et al. Effect of temozolomide on survival in elderly patients with glioblastoma and impaired performance status: a propensity score-matching analysis. Onco Targets Ther 2017;10:4029-35.

91. Bates JE, Youn P, Usuki KY, et al. Brain metastasis 
from melanoma: the prognostic value of varying sites of extracranial disease. J Neurooncol 2015;125:411-8.

92. Gebhardt BJ, Dobelbower MC, Ennis WH, et al. Patterns of failure for glioblastoma multiforme following limitedmargin radiation and concurrent temozolomide. Radiat Oncol 2014;9:130.

93. Cabrera AR, Kirkpatrick JP, Fiveash JB, et al. Radiation therapy for glioblastoma: Executive summary of an American Society for Radiation Oncology EvidenceBased Clinical Practice Guideline. Pract Radiat Oncol 2016;6:217-25.

94. Kruser TJ, Bosch WR, Badiyan SN, et al. NRG brain tumor specialists consensus guidelines for glioblastoma contouring. J Neurooncol 2019;143:157-66.

95. Kelly PJ, Daumas-Duport C, Scheithauer BW, et al. Stereotactic histologic correlations of computed tomography- and magnetic resonance imaging-defined abnormalities in patients with glial neoplasms. Mayo Clin Proc 1987;62:450-9.

96. Chang EL, Akyurek S, Avalos T, et al. Evaluation of peritumoral edema in the delineation of radiotherapy clinical target volumes for glioblastoma. Int J Radiat Oncol Biol Phys 2007;68:144-50.

97. Minniti G, Amelio D, Amichetti M, et al. Patterns of failure and comparison of different target volume delineations in patients with glioblastoma treated with conformal radiotherapy plus concomitant and adjuvant temozolomide. Radiother Oncol 2010;97:377-81.

98. Wirsching HG, Tabatabai G, Roelcke U, et al. Bevacizumab plus hypofractionated radiotherapy versus radiotherapy alone in elderly patients with glioblastoma: the randomized, open-label, phase II ARTE trial. Ann Oncol 2018;29:1423-30.

99. Le Rhun E, Parrott T, Estok T, et al. ACTR-30. EORTC 1608: a phase 1B study of TG02, an oral cyclin-dependent kinase $9 / 5$ inhibitor, in elderly patients with newly

Cite this article as: Saeed H, Tseng YD, Lo SS. Narrative review of palliative hypofractionated radiotherapy for high grade glioma. Ann Palliat Med 2021;10(1):846-862. doi: 10.21037/ apm-20-1246 diagnosed glioblastoma stratified by MGMT promoter methylation status. Neuro-Oncology 2016;18:vi8.

100.Stupp R, Taillibert S, Kanner AA, et al. Maintenance Therapy With Tumor-Treating Fields Plus Temozolomide vs. Temozolomide Alone for Glioblastoma: A Randomized Clinical Trial. JAMA 2015;314:2535-43.

101. Chambless LB, Kistka HM, Parker SL, et al. The relative value of postoperative versus preoperative Karnofsky Performance Scale scores as a predictor of survival after surgical resection of glioblastoma multiforme. J Neurooncol 2015;121:359-64.

102. Abhinav K, Aquilina K, Gbejuade H, et al. A pilot study of glioblastoma multiforme in elderly patients: treatments, O-6-methylguanine-DNA methyltransferase (MGMT) methylation status and survival. Clin Neurol Neurosurg 2013;115:1375-8.

103. Stupp R, Hegi ME, Mason WP, et al. Effects of radiotherapy with concomitant and adjuvant temozolomide versus radiotherapy alone on survival in glioblastoma in a randomised phase III study: 5-year analysis of the EORTC-NCIC trial. Lancet Oncol 2009;10:459-66.

104. Gittleman H, Lim D, Kattan MW, et al. An independently validated nomogram for individualized estimation of survival among patients with newly diagnosed glioblastoma: NRG Oncology RTOG 0525 and 0825. Neuro Oncol 2017;19:669-77.

105. Sulman EP, Ismaila N, Armstrong TS, et al. Radiation Therapy for Glioblastoma: American Society of Clinical Oncology Clinical Practice Guideline Endorsement of the American Society for Radiation Oncology Guideline. J Clin Oncol 2017;35:361-9.

106. Brazil L, Swampillai A, Mak K, et al. P01.072 Hydroxychloroquine and short course radiotherapy for elderly patients with glioma: a randomised study. NeuroOncology 2018;20:iii246. 